Article

\title{
Composite Films of Waterborne Polyurethane and Few-Layer Graphene-Enhancing Barrier, Mechanical, and Electrical Properties
}

\author{
Eunice Cunha ${ }^{1,2}$ and Maria C. Paiva ${ }^{2, *}$ \\ 1 National Graphene Institute and School of Materials, University of Manchester, Manchester M13 9PL, UK; \\ eunice.cunha-2@manchester.ac.uk \\ 2 Institute for Polymers and Composites, University of Minho, Campus of Azurém, 4804-533 Guimarães, \\ Portugal \\ * Correspondence: mcpaiva@dep.uminho.pt; Tel.: +351-253-510-320
}

Received: 9 March 2019; Accepted: 1 April 2019; Published: 3 April 2019

\begin{abstract}
Graphene has excellent mechanical, thermal, and electrical properties. Graphene can serve as potential reinforcement in polymer-based nanocomposites. In order to achieve this goal, graphene has to be distributed homogeneously and dispersed throughout the polymer matrix, establishing a strong interface with the polymer. Solution mixing is an interesting method for the preparation of homogeneous nanocomposites, in particular when using environmentally friendly solvents such as water. The major difficulty met in the production of graphene/polymer composites concerns the preparation and stabilization of graphene in aqueous suspension. In the present work three different graphite-based materials, with different crystallinity and purity grades, were exfoliated in aqueous solution of an amphiphilic pyrene derivative, forming few-layer graphene (FLG). The FLG prepared was dispersed in waterborne polyurethane (WPU) to produce composite films. The composite films were produced by solvent casting and spray coating, forming free-standing films that were characterized in terms of its distribution of FLG through the composite, its permeability to water vapor, its electrical resistivity, and its mechanical properties. The studies demonstrated the influence of different factors on the composite film properties such as the use of graphite vs. FLG, the FLG lateral dimensions, and the FLG composition and composite preparation method.
\end{abstract}

Keywords: few-layer graphene; waterborne polyurethane; composites; tensile properties; electrical conductivity; barrier properties

\section{Introduction}

Polyurethane (PU) is a versatile polymer with a wide range of applications. It has been extensively used as paints, adhesives, and coatings in the fields of construction, textiles, footwear, furniture, packaging, electronics, automotive, and aerospace, among others [1-8]. Most research performed with the focus on coating and adhesive applications use solvent-borne polyurethane. The use of organic solvents that are released to the atmosphere during the drying stage cause pollution and health problems, and thus alternative solutions are under development. Waterborne polyurethane (WPU) is an eco-friendly alternative to solvent-borne PU, which involves only water during the drying stage [9]. Furthermore, WPU typically presents excellent elasticity, abrasion resistance, and flexibility [1,9-11]. However, some of the properties of WPU such as its water resistance, thermostability, and mechanical properties are inferior to those of solvent-borne PU. Graphene has emerged as an interesting reinforcement candidate because of its extraordinary thermal, mechanical, and electronic properties [12]. The incorporation of graphene [13] and reduced 
graphene oxide [14-16] in a WPU matrix has been reported to improve the electrical, thermal, mechanical, and barrier properties of its nanocomposites. However, these nanomaterials tend to agglomerate through van der Waals interactions that may compromise their good dispersion in the polymer matrix. The surface modification of graphene provides an effective means of introducing specific functionalities that will enhance its compatibility and dispersion into polymer matrices. Graphene oxide (GO) has been used to produce well-dispersed WPU/GO nanocomposites with enhanced physical properties [17-22]. The oxygen groups on GO provide sites for further chemical reactions. The modification of GO with isophore diidocyanate (IPDI) and octadecylamine (ODA) [23], titane coupling agent [24], 3-aminopropyl triethoxysilane (APTES) [25,26], and hydramines (MEA - monorthanolamine, DEA—diethanolamine and TEA—triethylamine) [27] has been reported to improve the compatibly with a WPU matrix. The applications of graphene (pristine, oxidized, or functionalized)/WPU composites as electromagnetic interference (EMI) shielding devices [28-32], textiles [33,34], anticorrosives [24,35-38], and flame retardant coatings [39] have also been studied.

In the present work, graphite materials with different crystallinity and purity grades were exfoliated in an aqueous solution of a pyrene derivative to produce few-layer graphene (FLG). The FLG were, thus, dispersed in waterborne polyurethane (WPU) to produce composite films. Free standing composite films were formed by solvent casting and spray coating, and they were characterized for their distribution of FLG through the composite, their permeability to water vapor, and their electrical resistivity and mechanical properties. The studies allowed an assessment of the effect of graphite exfoliation, FLG morphology and its composition, on the composite film properties.

\section{Materials and Methods}

\subsection{Materials}

Graphite and graphite nanoplatelets were purchased from three different suppliers: (i) GnPC was purchased from XGSciences, Lansing, MI, USA, and was delivered as graphene with a lateral size distribution ranging from very small $(100 \mu \mathrm{m})$ to relatively large flakes $(1-2 \mu \mathrm{m})$, an average thickness of approximately $2 \mathrm{~nm}$, a typical average surface area of $750 \mathrm{~m}^{2} / \mathrm{g}$, and approximately 7 atom\% of oxygen; (ii) Micrograf HC11 was provided by Nacional de Grafite, São Paulo, Brasil, and it was a micronized graphite with a lateral size of about $10 \mu \mathrm{m}$; (iii) Graphexel grade 2369 was provided by Graphexel Ltd., Essex, UK, and it was a natural crystalline graphite with a lateral size of about $180 \mu \mathrm{m}$. The nomenclature adopted in this work was GnPC, Micrograf, and Graphexel, respectively. Waterborne polyurethane, grade ICO-THANE 10, was provided from I-Coats NV, Berchem, Belgium. The pyrene derivative (Py) was synthetized according to previous work described elsewhere [40].

\subsection{Preparation and Characterization of the Few-Layer/Waterborne Polyurethane (WPU) Composite Films}

Water suspensions of FLG obtained from GnPC, Micrograf, and Graphexel were prepared as described in [40]. GnPC, Micrograf, and Graphexel were added to the pyrene derivative (Py) aqueous solution $(0.05 \mathrm{mM})$, and the exfoliation of the starting graphite materials was carried out using sonication. The dispersions were then centrifuged to remove large agglomerates, and the supernatant was collected resulting in stable aqueous suspensions of few-layer graphene. The FLG suspensions were analyzed by UV-visible spectroscopy. The aqueous suspensions were mixed with WPU $(0.025$, 0.05, 0.1 , and $0.5 \mathrm{wt} . \%$ of FLG in WPU) using an Ultrasonic processor UP100H from Hielscher (Teltow, Germany), equipped with a sonotrode MS7D, for $1 \mathrm{~h}$. The mixtures were then cast onto a polypropylene plate mold and dried under ambient conditions for $48 \mathrm{~h}$. FLG/WPU composites with increasing FLG content (from 0.1 to $10.0 \mathrm{wt}$. \%) were prepared by spraying the suspensions onto a heated polypropylene plate $\left(60^{\circ} \mathrm{C}\right)$ used as a substrate. All the dried films (typically about $50 \mu \mathrm{m}$ thick) were cured at $80{ }^{\circ} \mathrm{C}$ for $6 \mathrm{~h}$. The as-received graphite-based materials/WPU composite films were also prepared for comparison. 
The mechanical property measurements were performed using a universal tensile testing machine, Instron 4505 (Norwood, MA, USA), at a crosshead speed of $25 \mathrm{~mm} / \mathrm{min}$ according to ASTM D 882. The results reported were the average of 10 specimen tests. Thermogravimetric analyses were performed on a Modulated TGA Q500 from TA Instruments, New Castle, DE, USA. The samples were heated at $10{ }^{\circ} \mathrm{C} / \mathrm{min}$ under a constant flow of $\mathrm{N}_{2}$. The Raman spectra were acquired on a Horiba Labram HR Evolution confocal microscope (Horiba Jobin Yvon, Palaiseau, France), equipped with a motorized $x-y$ stage, using an excitation laser with $532 \mathrm{~nm}$ and a $100 \times$ objective lens. The Raman maps were obtained from a $30 \times 35$ point array with a step size of $1.0 \mu \mathrm{m}$. All data were analyzed using the LabSpec 6 software (HORIBA, Jobin Yvon, Palaiseau, France). Volume resistivity measurements were carried out on a picoamperometer Kethley 6487 (A Tektronix Company, Cleveland, OH, USA) with Kethley electrodes 8009 . Three samples were prepared for each composition, and at least three measurements were acquired for each sample. Each acquired current value (for each applied voltage) was the result of an average of 100 measured values. The water vapor transmission (WVT) tests were performed using the desiccant method according to the standard of ASTM E96-66. Scanning electron microscopy (SEM) and scanning transmission electron microscopy (STEM) of the nanomaterials and of the cryo-fractured composite cross sections were performed on a NanoSEM FEI Nova 200 microscope (FEI Europe Company, Hillsboro, OR, USA) operating at $5 \mathrm{kV}$ (SEM) or $15 \mathrm{kV}$ (STEM). The composite cross-sections were previously coated with a $10 \mathrm{~nm}$ platinum layer.

\section{Results}

\subsection{Reinforcing Materials_Graphite and Few-Layer Graphene}

The produced FLG and its starting materials were characterized by SEM and STEM as well as UV-visible and Raman spectroscopies. Figure 1a-c shows the SEM images of the GnPC, Micrograf, and Graphexel starting materials, respectively, demonstrating their morphological differences in lateral size and thickness. Thermogravimetric analysis of the as-received GnPC (Figure 1d) showed a weight loss of about $7.5 \%$ at $800{ }^{\circ} \mathrm{C}$, corresponding to the thermal degradation of its oxygen-containing groups. Micrograf and Graphexel presented higher thermal stabilities compared to GnPC, showing a weight loss at $800{ }^{\circ} \mathrm{C}$ of $0.7 \%$ and $1.7 \%$, respectively.
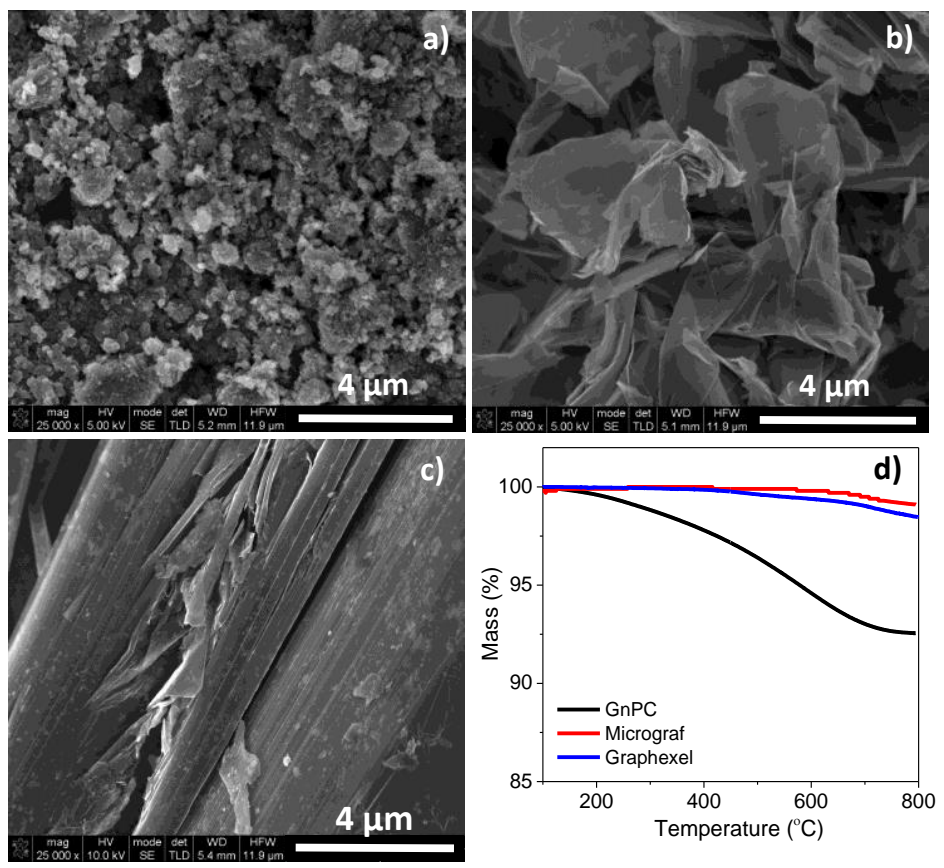

Figure 1. (a-c) Scanning electron microscopy (SEM) images and (d) thermogravimetric analysis of the GnPC, Micrograf, and Graphexel starting materials, respectively. 
The FLG aqueous suspensions prepared were analyzed by UV-visible spectroscopy (Figure 2a-c). The starting Py solution showed the typical absorption peaks between 200 and $600 \mathrm{~nm}$ [41], and the FLG suspensions spectra showed absorption over the whole wavelength range as expected for the graphene dispersions [42,43]. The suspensions of FLG from GnPC and Micrograf (Figure 2a,b) were highly concentrated for UV-visible analysis and, thus, were diluted $(10 \times$ and $2 \times$ respectively). The spectra of these stable FLG suspensions showed an absorption peak at about $265 \mathrm{~nm}$, which was similar to that of graphene and graphene oxide suspensions [41,44,45]. The Graphexel FLG suspensions (Figure 2c) presented considerable lower intensities, and the Py original peaks were barely visible for the FLG suspensions, which was reported to be due to the $\pi-\pi$ interactions between Py and exfoliated graphite $[40,41]$.

STEM images of the aqueous FLG suspensions (Figure $2 \mathrm{~d}-\mathrm{f}$ ) showed the formation of thin flakes with different lateral sizes depending on the lateral size of the starting material. The yield of FLG in suspension was calculated using the extinction coefficient values reported in previous work [40] and was shown in the UV-vis spectra of the FLG suspensions (Figure 2a-c). The concentration of GnPC FLG in suspension was found to be $450 \mu \mathrm{g} / \mathrm{mL}$, which represented $90 \%$ of the initial concentration of the graphite material. Micrograf FLG suspension presented a concentration of $91 \mu \mathrm{g} / \mathrm{mL}$ (18\% yield), and Graphexel FLG concentration was $31 \mu \mathrm{g} / \mathrm{mL}$ ( $6 \%$ yield).

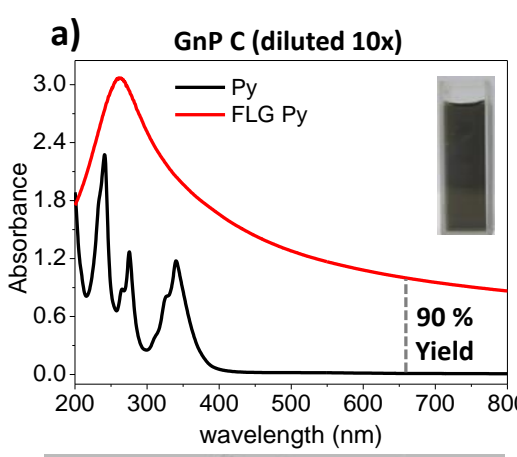

b) GnP Micrograf (diluted 2x)
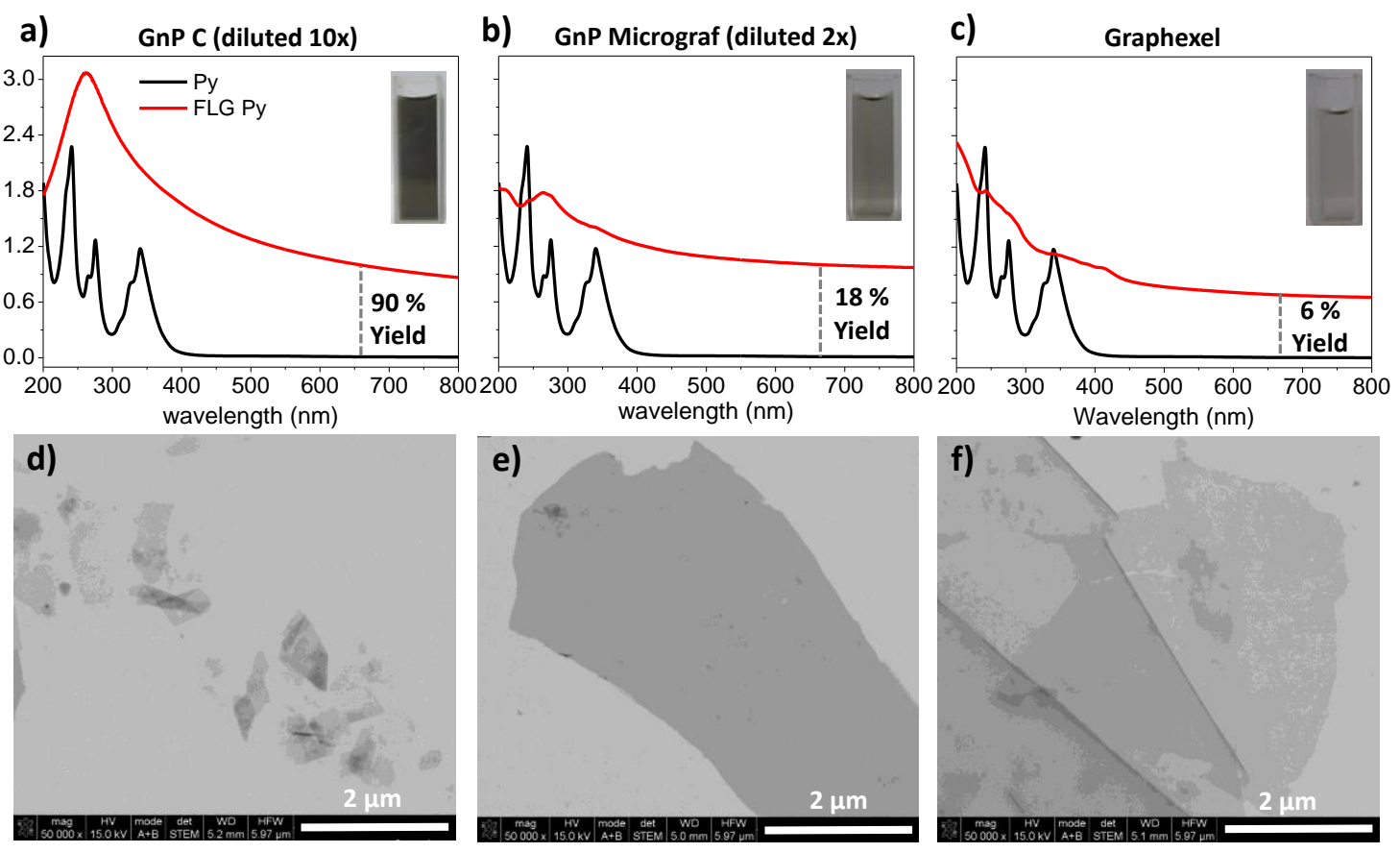

Figure 2. (a-c) UV-visible spectra of the few-layer graphene (FLG) suspensions obtained from GnPC, Micrograf, and Graphexel starting materials, respectively; (d-f) Scanning transmission electron microscopy images of the FLG GnPC, FLG Micrograf, and FLG Graphexel, respectively.

Raman spectroscopy is an important tool for the characterization of graphene and graphite-based materials, and it was used to evaluate the quality of these materials and their exfoliation into FLG $[46,47]$. A previous statistical study performed with Raman spectroscopy demonstrated that the exfoliation of Graphexel and Micrograf in Py solution yielded approximately 80\% of FLG, while GnPC yielded approximately 30\% of FLG [40]. However, GnPC flakes have small lateral sizes and are already highly exfoliated in the starting material, thus forming concentrated aqueous suspensions. The graphite-based suspensions used in this work for composite preparation were characterized before and after exfoliation. Typical Raman spectra of Graphexel, Micrograf, and GnPC are presented in Figure 3. The Raman spectrum of Graphexel (Figure 3a) was typical of graphite. The G band was present at $1581 \mathrm{~cm}^{-1}$. The $\mathrm{D}$ band, which normally is observed around $1350 \mathrm{~cm}^{-1}$, was barely 
identified, indicating the good structural quality of this graphite. The 2D band position occurred at $2722 \mathrm{~cm}^{-1}$, presenting the typical asymmetric shape observed for graphite. Conversely, the FLG Graphexel (Figure 3a) showed a down-shift of the 2D band to $2702 \mathrm{~cm}^{-1}$ and a more symmetric shape indicating the formation of more exfoliated flakes. The D band of FLG Graphexel presented higher intensity compared to its starting material, which may be related to the presence of Py at the surface of the exfoliated material [48]. Also, the characteristic peaks of Py can be observed in these spectra.

Micrograf (Figure 3b) presented a less asymmetric 2D band compared to Graphexel, indicating a higher level of exfoliation of the micronized graphite. Similar to Graphexel, Micrograf exfoliated in Py solution presented a 2D band typical of FLG material (Figure 3a,b). The Raman spectra of the GnPC and Py-exfoliated GnPC are presented in Figure 3c. The GnPC starting material showed a prominent $D$ band near $1350 \mathrm{~cm}^{-1}$, with a slightly higher intensity than the $G$ band (at $1581 \mathrm{~cm}^{-1}$ ), which may be related to its oxidation level as well as its smaller flake size, and, thus, higher edge-to-basal plane ratio. The 2D band position occurred near $2692 \mathrm{~cm}^{-1}$, showing high symmetry, although with lower intensity compared to the G band. The large down-shift of the 2D band of GnPC compared to Graphexel and Micrograf was an indication of a higher degree of exfoliation. However, after the Py exfoliation process (FLG GnPC), the D band presented a lower intensity relative to the G band, which may have resulted from the selective adsorption of the more graphitic (less oxidized) flakes by the pyrene derivatives. The less "defective" GnPC may adsorb higher amounts of pyrene and, thus, may be more stable in aqueous suspension. Furthermore, the 2D band position was up-shifted, and it was similar to the exfoliated FLG Micrograf and FLG Graphexel spectra.
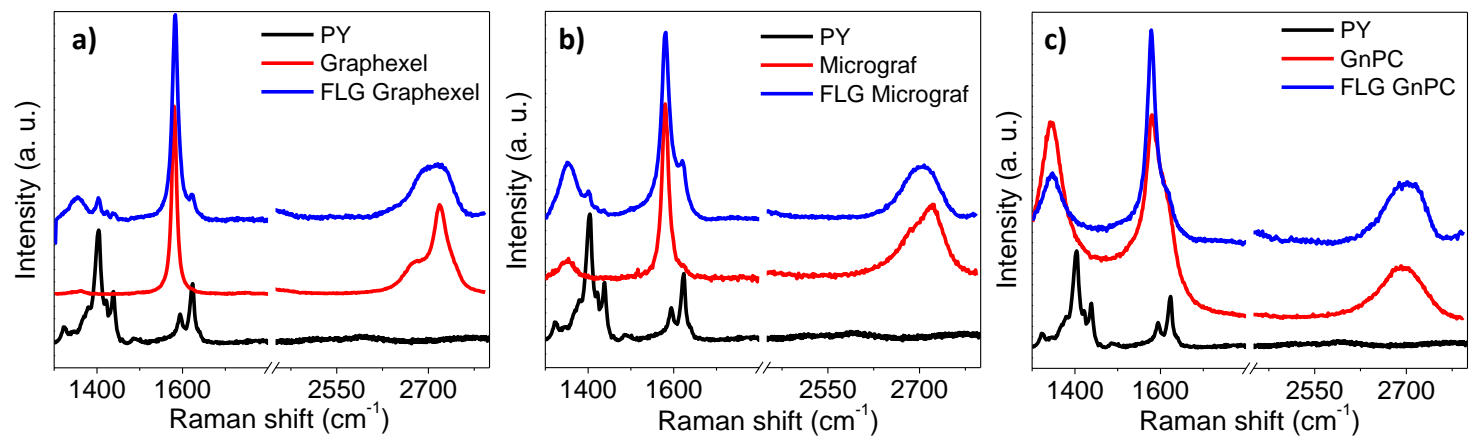

Figure 3. (a-c) Raman spectra of the Graphexel, Micrograf, and GnPC starting materials and its correspondent FLG, respectively.

\subsection{Nanocomposite Films-Low Composition Range}

The GnPC, Micrograf, and Graphexel FLG suspensions were mixed with waterborne polyurethane. Films of FLG/WPU at low loading levels, from $0.025 \mathrm{wt} . \%$ to $0.5 \mathrm{wt} . \%$, were prepared by solvent casting. WPU composite films with as-received graphite materials were produced for comparison. The mechanical properties of all WPU composite films were evaluated, and the results were depicted in Figure 4. In general, the composite mechanical properties were enhanced with the incorporation of the pristine graphitic materials as well as with the FLG (obtained from GnPC, Micrograf, and Graphexel). Furthermore, the FLG composite films presented enhanced mechanical properties compared to the pristine graphite composite films. At these low FLG contents, dispersion into the WPU matrix was enhanced and facilitated by the non-covalent functionalization with Py. The poor interaction of the pristine graphite materials with water and WPU may be responsible for the formation of agglomerates, with a negative influence upon the composite mechanical properties [49]. The ultimate elongation tended to decrease for the WPU composites compared to the WPU films, and this effect was more pronounced for the FLG composites. This indicated that the functionalized FLG may act as functional cross-linkers and constrain the motion of the segments because of the stronger interaction with WPU. 


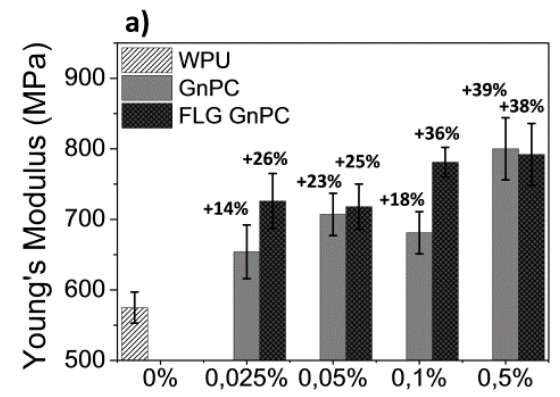

\section{b)}
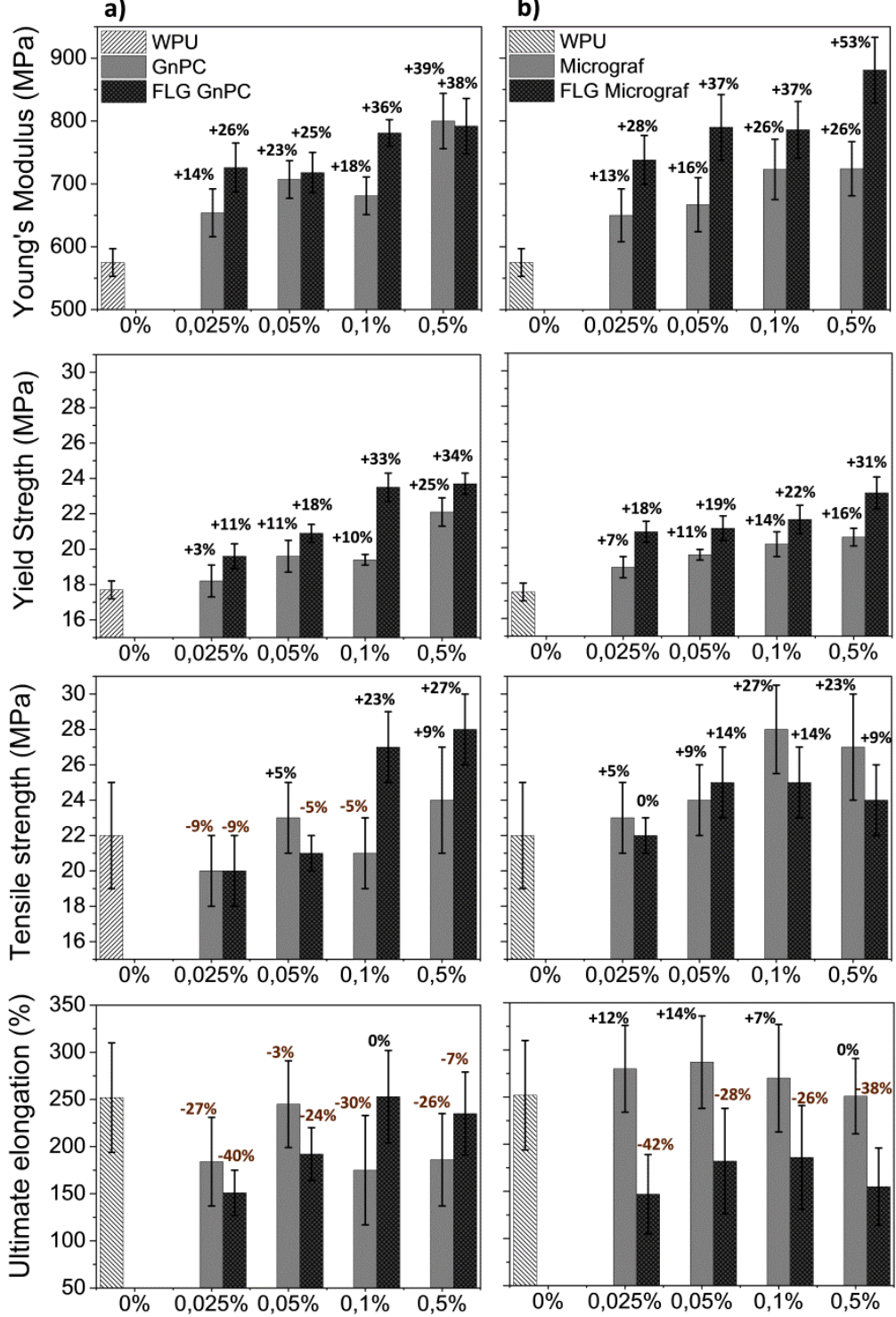
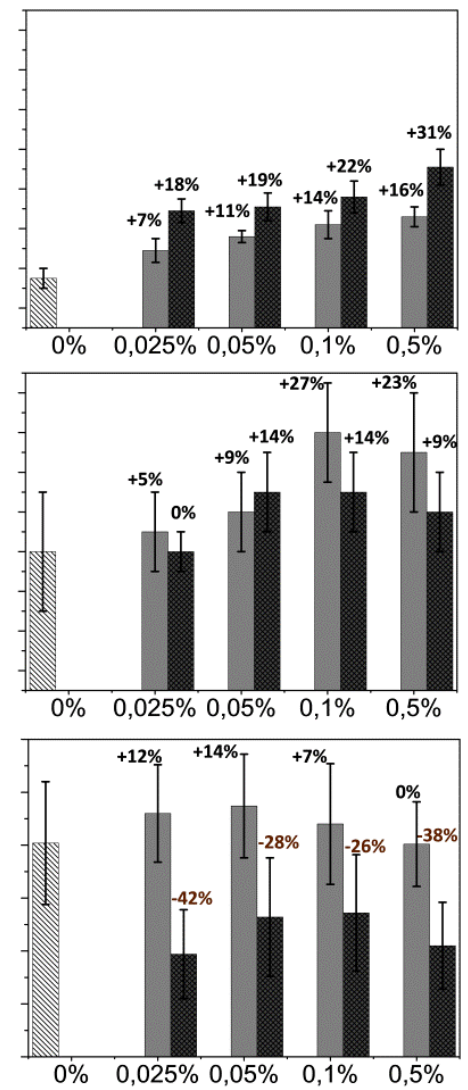

c)
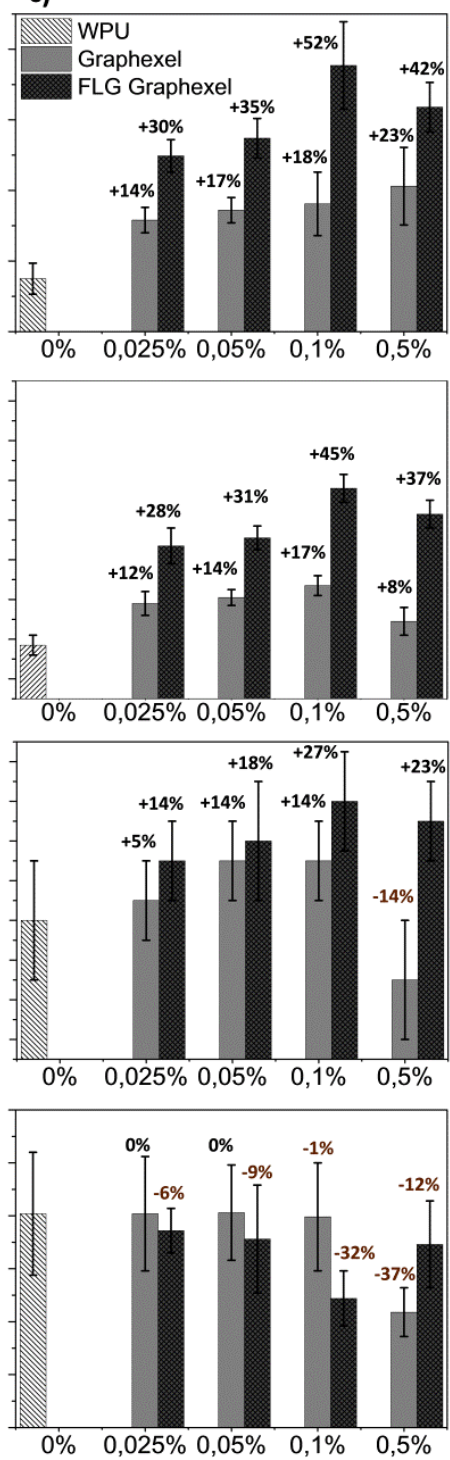

Figure 4. Young's modulus, yield strength, tensile strength, and ultimate elongation of the waterborne polyurethane (WPU) composite films at different loadings of graphitic starting material and FLG for (a) GnPC, (b) Micrograf, and (c) Graphexel. The \% values indicate the increase/decrease relative to WPU films.

Figure 5 shows SEM images of the WPU composite films at $0.5 \mathrm{wt} . \%$ loading. The images show good interfacial adhesion between the graphitic fillers and the WPU matrix, in agreement with results of the mechanical properties discussed above. Larger agglomerates were observed for the Graphexel/WPU composites, which can be related with the drop in mechanical properties compared to the FLG Graphexel/WPU composites. 

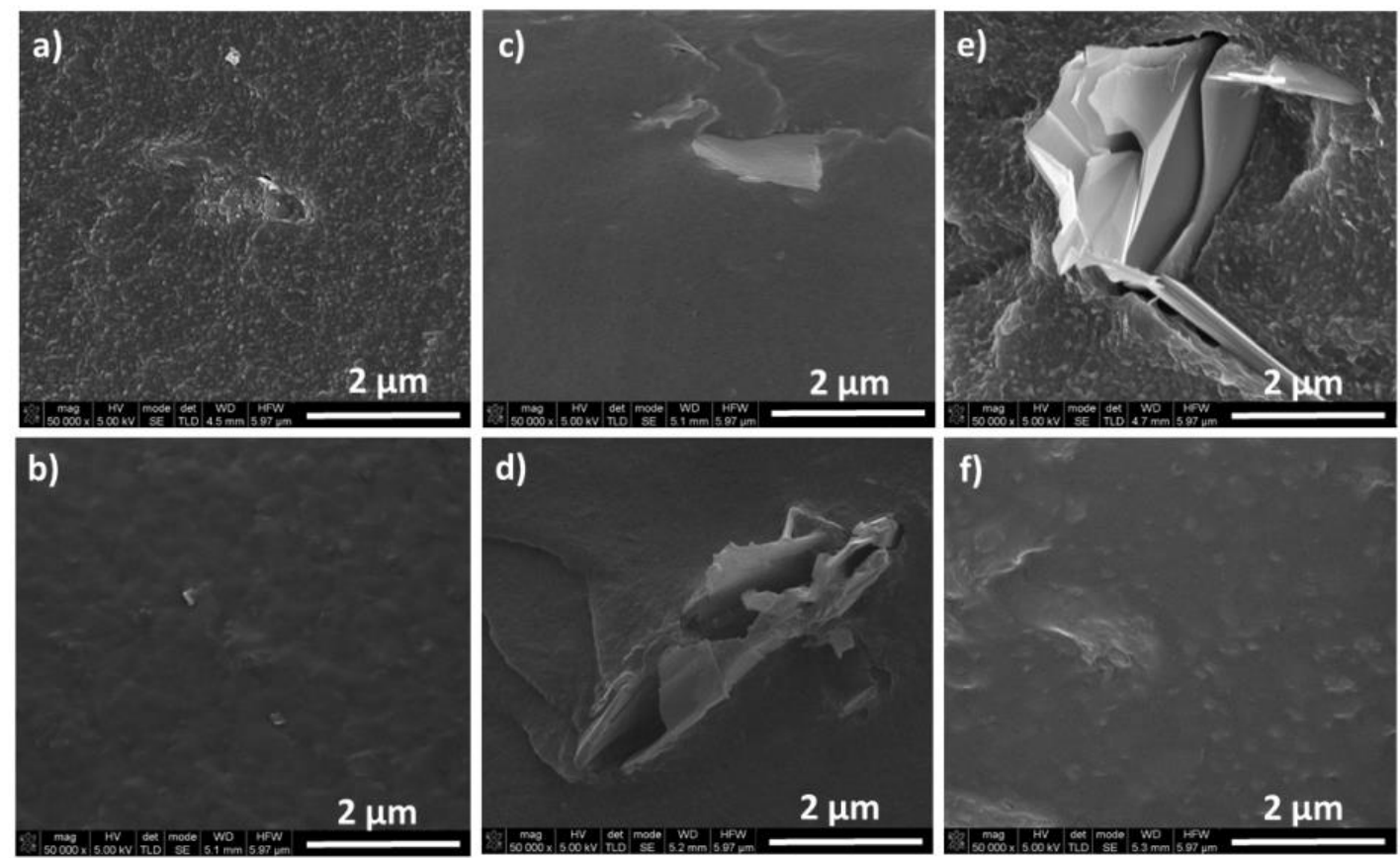

Figure 5. SEM images of 0.5 wt.\% WPU composites of: (a) GnPC, (b) FLG GnPC, (c) Micrograf, (d) FLG Micrograf, (e) Graphexel, and (f) FLG Graphexel.

The distributions of the GnPC, FLG GnPC, Micrograf, FLG Micrograf, Graphexel, and FLG Graphexel in the WPU matrix were analyzed by Raman spectroscopy, mapping the relative intensity of the graphite G-band to the WPU $1450 \mathrm{~cm}^{-1}$ band $\left(\mathrm{I}_{\mathrm{G}} / \mathrm{I}_{1450}\right)$ over a cross-section area of $30 \times 35 \mu \mathrm{m}^{2}$. The typical spectra in the region from $1000 \mathrm{~cm}^{-1}$ to $1800 \mathrm{~cm}^{-1}$ for the WPU, the pristine graphitic materials and their WPU composites at $0.5 \mathrm{wt} . \%$, are shown in Figure 6a-c. Figures $6 \mathrm{~d}-\mathrm{f}$ and 6j-1 show the optical microscopy images of the composite cross-sections analyzed for GnPC, Micrograf, and Graphexel, as well as the FLG GnPC, FLG Micrograf, and FLG Graphexel composites, respectively. Figures $6 \mathrm{~g}-\mathrm{i}$ and $6 \mathrm{~m}-\mathrm{o}$ shows the color-coded Raman mapping of $\mathrm{I}_{\mathrm{G}} / \mathrm{I}_{1450}$ for the same composites. To facilitate the comparison, the $\mathrm{I}_{\mathrm{G}} / \mathrm{I}_{1450}$ were normalized into the range of $(0,5)$ in the color-coded Raman mapping. The maps depicted lower intensity variations for the FLG/WPU composites compared to the corresponding pristine materials/WPU composites. FLG, formed by thinner flakes that were non-covalently functionalized to increase compatibility with the polymer, was uniformly distributed in the WPU matrix. The filler dispersion can be quantified by calculating the standard deviation for the $\mathrm{I}_{\mathrm{G}} / \mathrm{I}_{1450}$ data set of the Raman mapping, as reported before [50]. Higher standard deviation values corresponded to a larger variation on the $\mathrm{I}_{\mathrm{G}} / \mathrm{I}_{1450}$, representing a less homogeneous dispersion. In the present work the standard deviation values of the $\mathrm{I}_{\mathrm{G}} / \mathrm{I}_{1450}$ for the GnPC/WPU and FLG GnPC/WPU composites were 1.4 and 0.7, respectively, and for Micrograf/WPU, FLG Micrograf/WPU, Graphexel/WPU, and FLG Graphexel/WPU composites the standard deviation values were $8.9,2.0,11.3$, and 7.8., respectively. It is therefore clear that: (i) better dispersion was achieved for the FLG WPU composites, probably because of their smaller sheet thickness and better compatibility with the WPU matrix; (ii) as the particle lateral size increased from GnPC to Micrograf and to Graphexel, the dispersion appeared less homogeneous, possibly as a result of the formation of larger agglomerates in the WPU matrix. Despite the lower dispersion state of the pristine graphite materials, there was still a positive effect in the mechanical properties when compared to the neat WPU, as depicted in Figure 4. 

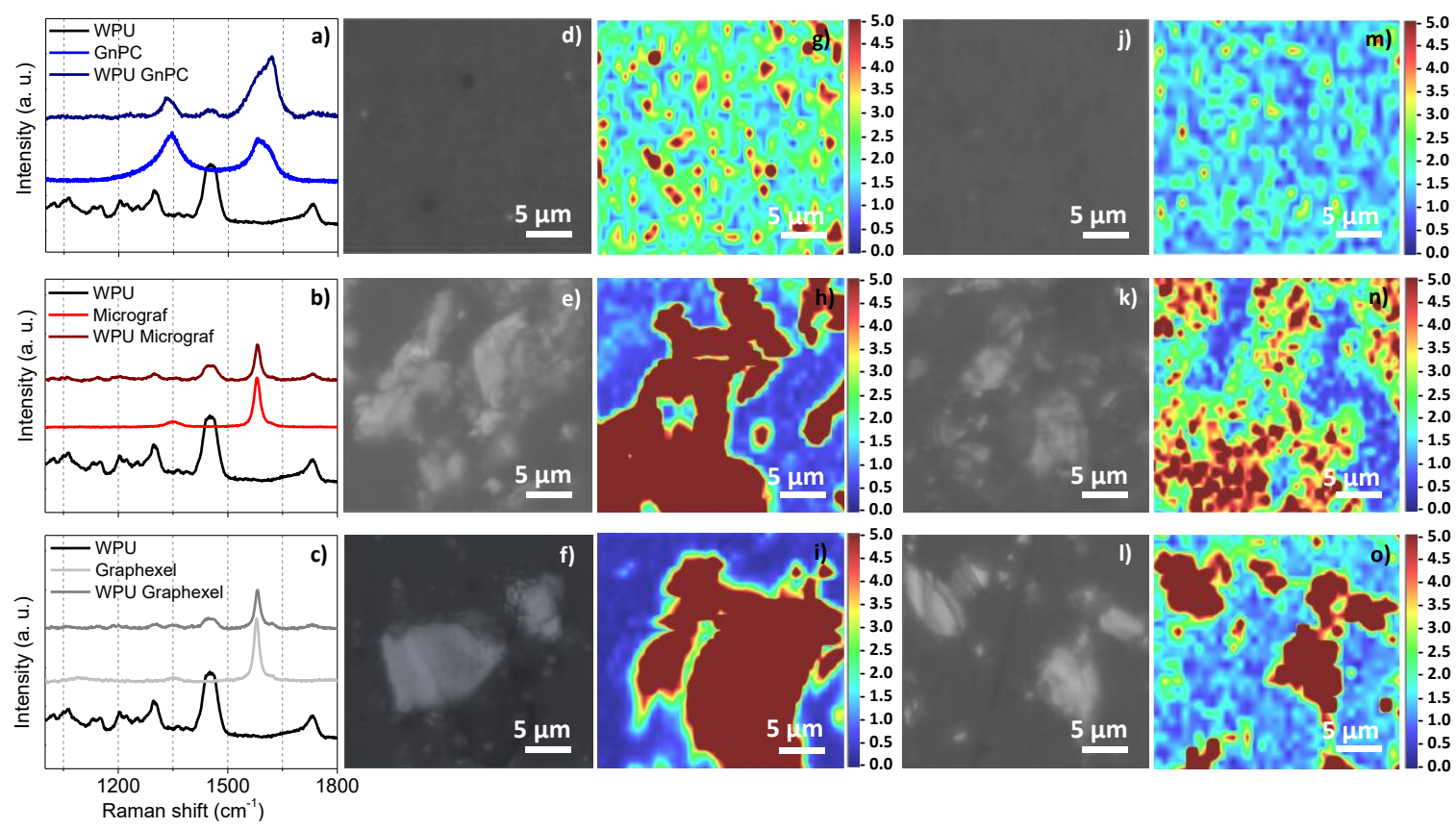

Figure 6. (a-c) Representative Raman spectra of WPU, graphitic starting material, and its corresponded WPU composites for GnPC, Micrograf, and Graphexel, respectively; (d-f) optical microscopy images and (g-i) color-coded Raman mapping for the GnPC, Micrograf, and Graphexel WPU composites at 0.5 wt.\%, respectively; $(\mathbf{j}-\mathbf{1})$ optical microscopy images and $(\mathbf{m}-\mathbf{o})$ color-coded Raman mapping for the FLG GnPC, FLG Micrograf and FLG Graphexel WPU composites at $0.5 \mathrm{wt}$ \% \%, respectively.

The coefficient of moisture permeability $\left(\mathrm{P}\left(\mathrm{H}_{2} \mathrm{O}\right)\right)$ of the composite films of as-received graphite and FLG was calculated according to the specifications of ASTM E96. The results obtained for $\mathrm{P}\left(\mathrm{H}_{2} \mathrm{O}\right)$ of WPU and WPU composite films at $0.5 \mathrm{wt} . \%$ loading are presented in Figure 7a. It was observed that the incorporation of the graphite materials (pristine and FLG) reduced the value of $\mathrm{P}\left(\mathrm{H}_{2} \mathrm{O}\right)$. For the films containing GnPC and FLG GnPC no significant difference was observed, both films induced a decrease of $19 \%$ for $\mathrm{P}\left(\mathrm{H}_{2} \mathrm{O}\right)$ relative to the WPU films. A decrease of approximately $10 \%$ in permeability was observed for films with Micrograf and Graphexel, however for FLG Micrograf and FLG Graphexel the decrease in permeability relative to WPU films was further enhanced to $28 \%$ and $39 \%$, respectively, showing the effectiveness of FLG as a barrier to moisture. The higher performance of FLG Graphexel may be attributed to its larger flake lateral size. In fact it was reported that large lateral size particles as well as large aspect ratios enhanced the barrier properties even for randomly orientated fillers into the matrix [51,52]. Furthermore, the FLG/WPU composite films prepared in this work presented a higher barrier performance compared to other results reported in the literature. Yousefi et al. reported a decrease in $\mathrm{P}\left(\mathrm{H}_{2} \mathrm{O}\right)$ of $25 \%$ relative to WPU for GO/WPU 0.5wt.\% composite [21], and a decrease of $28 \%$ for highly oriented reduced GO/polyurethane composites [22], while Wang et al. found a decrease of $6 \%$ in $\mathrm{P}\left(\mathrm{H}_{2} \mathrm{O}\right)$ for $\mathrm{MoS}_{2} / \mathrm{WPU} 0.5 \mathrm{wt}$. $\%$ composite [53].

The electrical properties of the composite films were evaluated. The results are presented in Figure $7 \mathrm{~b}$. 
a)

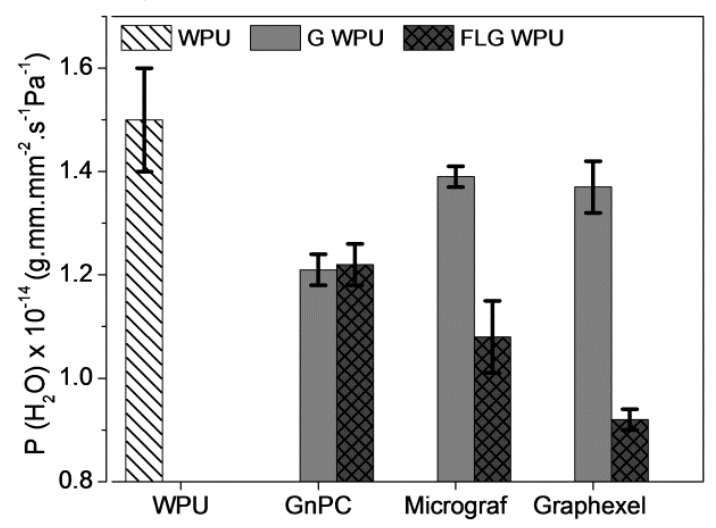

b)

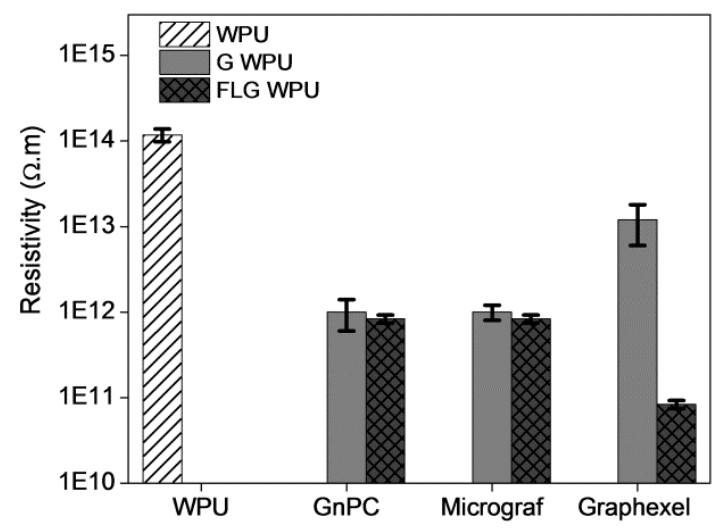

Figure 7. (a) Coefficient of moisture permeability and (b) electrical resistivity of the WPU composites at 0.5 wt. $\%$ loading.

The electrical resistivity of the GnPC and Micrograf composite films were similar for the pristine graphite and FLG, showing a decrease of about two orders of magnitude when compared with neat WPU. Pristine Graphexel/WPU decreased by nearly one order of magnitude; however, for FLG Graphexel/WPU composite films, the electrical resistivity decreased by three orders of magnitude relative to WPU films. Although all composite films were electrically insulating, there was a neat electrical resistivity decrease with the incorporation of all the graphite derivatives. Moreover, it was remarkable that even at a low graphite content the electrical properties of the films decreased, although the percolation threshold for graphene/WPU composites was typically well above $1.0 \mathrm{wt} . \%$.

\subsection{Nanocomposite Films_-High Composition Range}

WPU composite films filled with as-received Micrograf and FLG Micrograf at high loading levels, from 0.1 to $10.0 \mathrm{wt} . \%$, were prepared by spray coating. The mechanical properties of all composite films are presented in Figure 8a-d. The FLG/WPU films were observed to present higher mechanical performances than pristine Micrograf/WPU films, in agreement with the results obtained for the solvent cast films with low graphite or FLG compositions. The Young's modulus (Figure 8a) increased up to $40 \%$ at $4.0 \mathrm{wt}$.\% loading for pristine Micrograf/WPU films, while for FLG Micrograf/ WPU films it increased up to $85 \%$ at $8 \mathrm{wt} . \%$ loading, stabilizing at higher loading levels. Similarly, the yield and tensile strengths (Figure $8 \mathrm{c}, \mathrm{d}$ ) increased up to $4.0-5.0 \mathrm{wt}$.\% loadings, reaching higher values for the FLG composite films. The higher modulus and strength observed for the FLG/WPU films relative to Micrograf/WPU films reflected the enhancement in interfacial strength induced by the non-covalent functionalization with Py. The ultimate elongation (Figure 8b) did not decrease relative to WPU films at loadings below $5 \mathrm{wt}$ \%, even attaining a significant improvement at low loadings. These results showed that composite films with good mechanical properties may be produced by spray coating with graphite or FLG contents up to $5.0 \mathrm{wt} . \%$. 

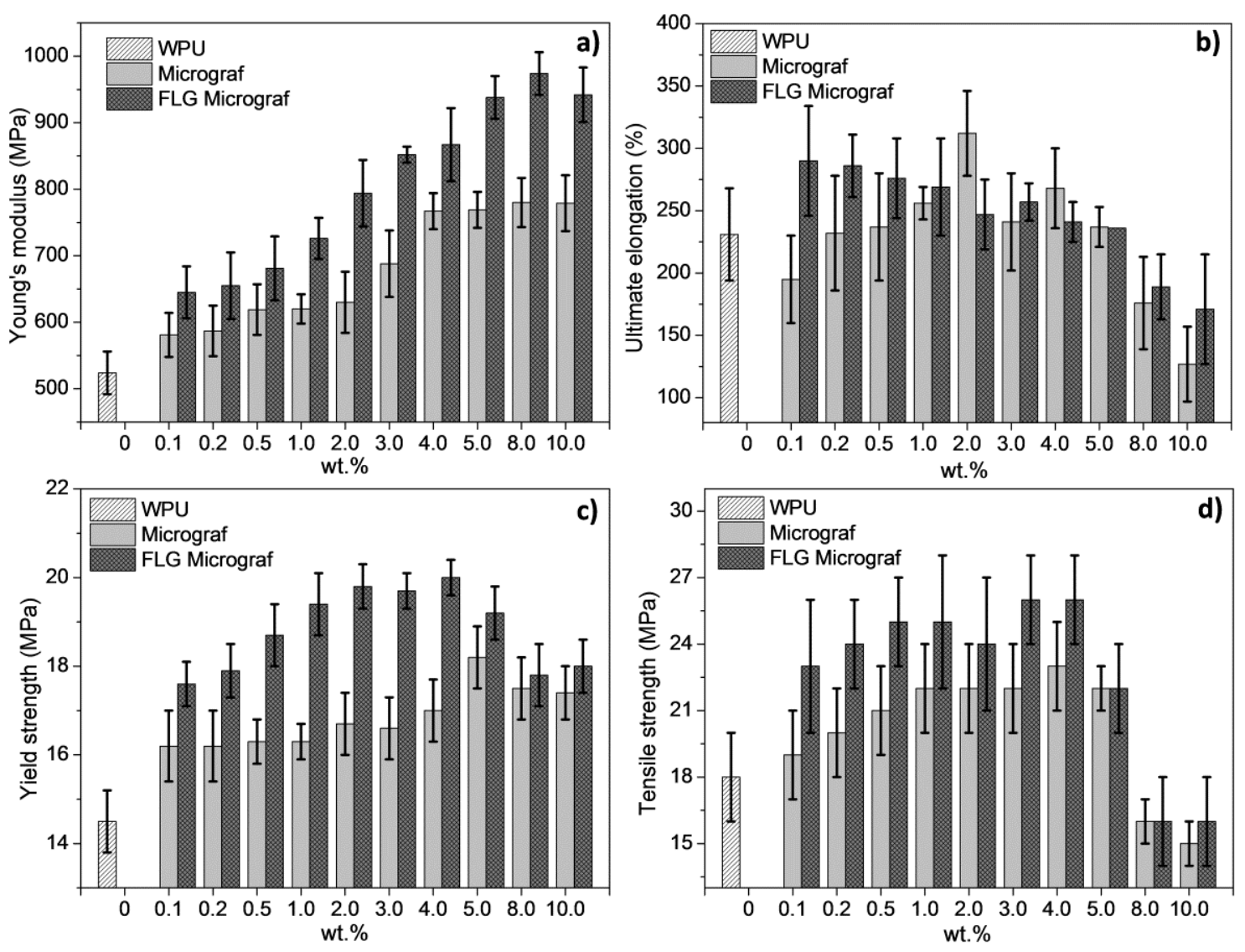

Figure 8. (a) Young's modulus, (b) ultimate elongation, (c) yield strength, and (d) tensile strength of the Micrograf and FLG Micrograf WPU composite films at different loadings.

The electrical conductivity of the WPU composite films, represented in Figure 9a, increased with pristine and FLG Micrograf content. The electrical percolation was reached at 4.0-5.0 wt.\% for pristine Micrograf/WPU and 3.0-4.0 wt.\% for the FLG Micrograf/WPU composite films. The lower electrical percolation observed for the FLG Micrograf/WPU composites reflected the higher exfoliation degree of FLG, induced by the non-covalent functionalization of Micrograf, that acted without damaging the $\mathrm{sp}^{2}$ structure of the FLG carbon structure. Thus, there was no loss of electrical conductivity.

The moisture permeability for the pristine and FLG Micrograf WPU films with 0.5, 2.0, and 5.0 wt.\% loadings is presented in Figure 9b. The incorporation of both pristine and FLG Micrograf in WPU led to a decrease in the moisture permeability with increasing loading, with higher performance of the FLG /WPU films, reaching a decrease in $\mathrm{P}\left(\mathrm{H}_{2} \mathrm{O}\right)$ of up to $63 \%$ at 5 wt.\% FLG. Higher barrier to moisture was achieved for the spray-coated versus cast films, at least for $0.5 \mathrm{wt} . \%$ Micrograf and FLG Micrograf/WPU films. Micrograf and FLG/WPU films reached $1.4 \times 10^{-14}$ and $1.1 \times 10^{-14} \mathrm{~g} \cdot \mathrm{mm} \cdot \mathrm{mm}^{-2} \cdot \mathrm{s}^{-1} \cdot \mathrm{Pa}^{-1}$, respectively, for cast films, and decreased to $0.9 \times 10^{-14}$ and $0.78 \times 10^{-14} \mathrm{~g} \cdot \mathrm{mm} \cdot \mathrm{mm}^{-2} \cdot \mathrm{s}^{-1} \cdot \mathrm{Pa}^{-1}$, respectively, for the spray-coated films. This considerable enhancement may be due to orientation effects induced by the spray deposition process. The orientation was confirmed by SEM (Figure 9c,d) showing that the pristine and FLG Micrograf were generally aligned parallel to the top surface of the nanocomposite films. 

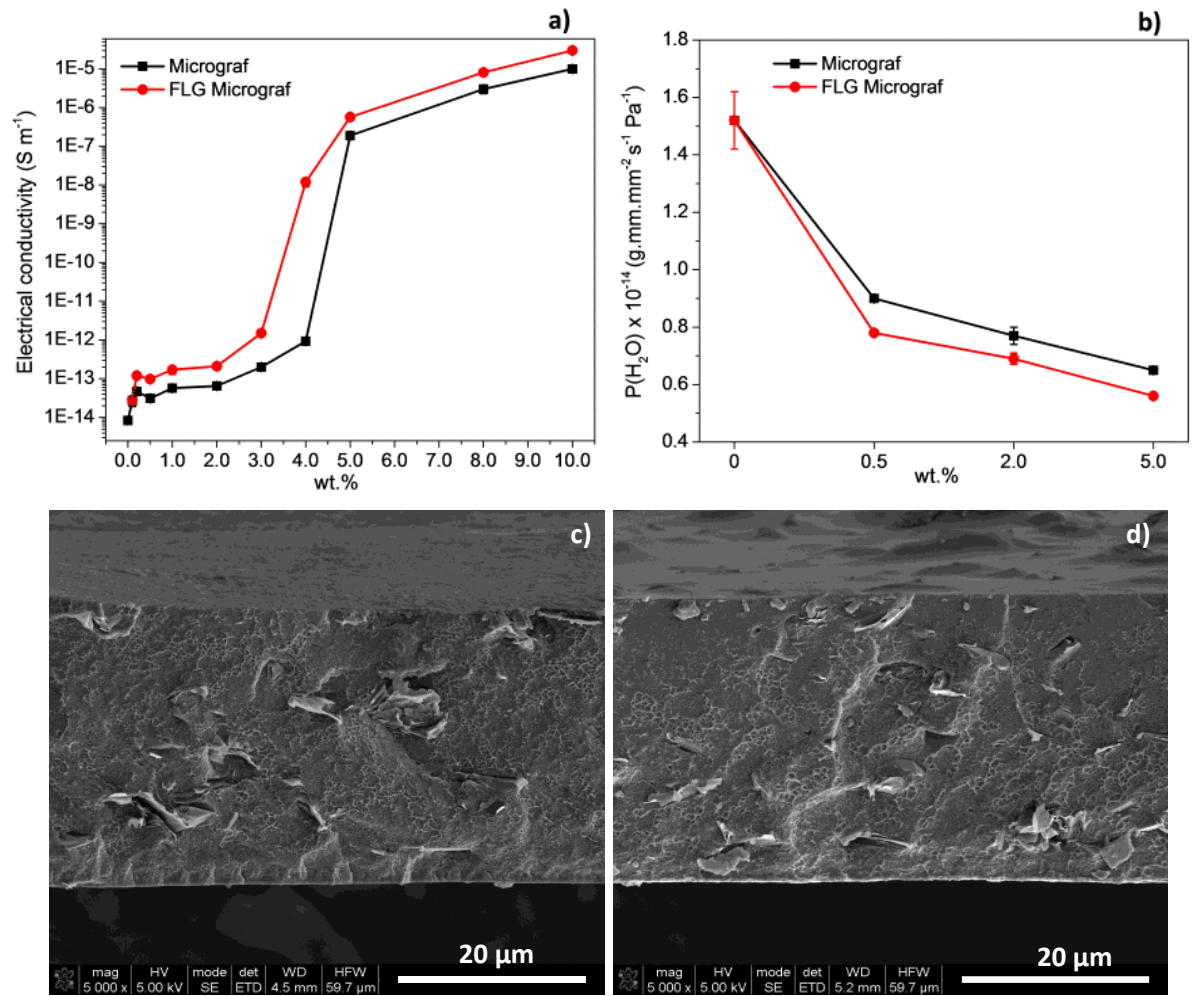

Figure 9. (a) Electrical conductivity; (b) coefficient of moisture permeability; and SEM images for the Micrograf (c) and FLG Micrograf WPU (d) composite films at different loadings.

\section{Conclusions}

Three graphite-based materials with different crystallinity and purity grades were exfoliated in aqueous solution of an amphiphilic pyrene derivative, forming few-layer graphene. The FLG formation was confirmed by Raman and UV-visible spectroscopies and imaged by STEM. The composite films produced with FLG/WPU exhibited high mechanical performance showing an increase of Young's modulus up to $85 \%$ at $8 \mathrm{wt}$. $\%$ FLG loading. The moisture barrier properties were enhanced by the incorporation of FLG, the larger flake size graphite resulting in higher barrier performance. The FLG/WPU films produced by spray coating showed higher moisture barrier properties compared to the solvent cast films, possibly due to orientation effects induced by the deposition process, reaching a decrease in moisture permeability of $63 \%$ at $5 \mathrm{wt} . \%$ FLG loading. Electrical percolation was reached in the range of 3.0 to $4.0 \mathrm{wt} . \%$ FLG, increasing by at least $1 \mathrm{wt} . \%$ for composite films with pristine graphite.

Author Contributions: Conceptualization, M.C.P. and E.C.; Methodology, E.C. and M.C.P.; Investigation, E.C.; Writing-Original Draft Preparation, E.C.; Writing-Review \& Editing, M.C.P.; Supervision, M.C.P.

Funding: This work was funded by National Funds through the FCT_-Portuguese Foundation for Science and Technology, Reference UID/CTM/50025/2013, and FEDER funds through the COMPETE 2020 Program under the project number POCI-01-0145-FEDER-007688. EC acknowledges the PhD grant SFRH/BD/87214/2012.

Conflicts of Interest: The authors declare no conflict of interest.

\section{References}

1. Chattopadhyay, D.K.; Raju, K.V. Structural engineering of polyurethane coatings for high performance applications. Prog. Polym. Sci. 2007, 32, 352-418. [CrossRef]

2. Crawford, D.M.; Escarsega, J.A. Dynamic mechanical analysis of novel polyurethane coating for military applications. Thermochim. Acta 2000, 357, 161-168. [CrossRef]

3. Hu, J.L.; Meng, H.P.; Li, G.Q.; Ibekwe, S.I. A review of stimuli-responsive polymers for smart textile applications. Smart Mater. Struct. 2012, 21, 053001. [CrossRef] 
4. Kathalewar, M.S.; Joshi, P.B.; Sabnis, A.S.; Malshe, V.C. Non-isocyanate polyurethanes: From chemistry to applications. RSC Adv. 2013, 3, 4110-4129. [CrossRef]

5. Lomax, G.R. Breathable polyurethane membranes for textile and related industries. J. Mater. Chem. 2007, 17, 2775-2784. [CrossRef]

6. Nasar, A.S.; Srinivasan, G.; Mohan, R.; Radhakrishnan, G. Polyurethane solvent-based adhesives for footwear applications. J. Adhes. 1998, 68, 21-29. [CrossRef]

7. Xiang, C.; Cox, P.J.; Kukovecz, A.; Genorio, B.; Hashim, D.P.; Yan, Z.; Peng, Z.; Hwang, C.C.; Ruan, G.; Samuel, E.L.; et al. Functionalized low defect graphene nanoribbons and polyurethane composite film for improved gas barrier and mechanical performances. ACS Nano 2013, 7, 10380-10386. [CrossRef] [PubMed]

8. Zhao, W.M.; Li, M.; Peng, H.X. Functionalized mwnt-doped thermoplastic polyurethane nanocomposites for aerospace coating applications. Macromol. Mater. Eng. 2010, 295, 838-845. [CrossRef]

9. Noble, K.L. Waterborne polyurethanes. Prog. Org. Coat. 1997, 32, 131-136. [CrossRef]

10. Xiao, Y.; Fu, X.W.; Zhang, Y.Y.; Liu, Z.M.; Jiang, L.; Lei, J.X. Preparation of waterborne polyurethanes based on the organic solvent-free process. Green Chem. 2016, 18, 412-416. [CrossRef]

11. Zhou, X.; Li, Y.; Fang, C.Q.; Li, S.J.; Cheng, Y.L.; Lei, W.Q.; Meng, X.J. Recent advances in synthesis of waterborne polyurethane and their application in water-based ink: A review. J. Mater. Sci. Technol. 2015, 31, 708-722. [CrossRef]

12. Geim, A.K.; Novoselov, K.S. The rise of graphene. Nat. Mater. 2007, 6, 183-191. [CrossRef] [PubMed]

13. Krol, P.; Krol, B.; Zenker, M.; Subocz, J. Composites prepared from the waterborne polyurethane cationomers-modified graphene. Part ii. Electrical properties of the polyurethane films. Colloid Polym. Sci. 2015, 293, 2941-2947. [CrossRef]

14. Choi, S.H.; Kim, D.H.; Raghu, A.V.; Reddy, K.R.; Lee, H.I.; Yoon, K.S.; Jeong, H.M.; Kim, B.K. Properties of graphene/waterborne polyurethane nanocomposites cast from colloidal dispersion mixtures. J. Macromol. Sci. B 2012, 51, 197-207. [CrossRef]

15. Lee, Y.R.; Raghu, A.V.; Jeong, H.M.; Kim, B.K. Properties of waterborne polyurethane/functionalized graphene sheet nanocomposites prepared by an in situ method. Macromol. Chem. Phys. 2009, 210, 1247-1254. [CrossRef]

16. Raghu, A.V.; Lee, Y.R.; Jeong, H.M.; Shin, C.M. Preparation and physical properties of waterborne polyurethane/functionalized graphene sheet nanocomposites. Macromol. Chem. Phys. 2008, 209, 2487-2493. [CrossRef]

17. Ding, J.N.; Fan, Y.; Zhao, C.X.; Liu, Y.B.; Yu, C.T.; Yuan, N.Y. Electrical conductivity of waterborne polyurethane/graphene composites prepared by solution mixing. J. Compos. Mater. 2012, 46, 747-752. [CrossRef]

18. Kim, Y.J.; Kim, B.K. Synthesis and properties of silanized waterborne polyurethane/graphene nanocomposites. Colloid Polym. Sci. 2014, 292, 51-58. [CrossRef]

19. Li, P.L.; Ren, H.; Qiu, F.X.; Xu, J.C.; Yu, Z.P.; Yang, P.F.; Xu, B.B.; Jiang, Y.; Yang, D.Y. Preparation and properties of graphene oxide-modified waterborne polyurethane-acrylate hybrids. Polym. Plast. Technol. 2014, 53, 1408-1416. [CrossRef]

20. Wu, S.L.; Shi, T.J.; Zhang, L.Y. Latex co-coagulation approach to fabrication of polyurethane/graphene nanocomposites with improved electrical conductivity, thermal conductivity, and barrier property. J. Appl. Polym. Sci. 2016, 133, 13. [CrossRef]

21. Yousefi, N.; Gudarzi, M.M.; Zheng, Q.B.; Aboutalebi, S.H.; Sharif, F.; Kim, J.K. Self-alignment and high electrical conductivity of ultralarge graphene oxide-polyurethane nanocomposites. J. Mater. Chem. 2012, 22, 12709-12717. [CrossRef]

22. Yousefi, N.; Gudarzi, M.M.; Zheng, Q.B.; Lin, X.Y.; Shen, X.; Jia, J.J.; Sharif, F.; Kim, J.K. Highly aligned, ultralarge-size reduced graphene oxide/polyurethane nanocomposites: Mechanical properties and moisture permeability. Compos. Part A 2013, 49, 42-50. [CrossRef]

23. Luo, X.M.; Zhang, P.; Ren, J.; Liu, R.; Feng, J.Y.; Ge, B.H. Preparation and properties of functionalized graphene/waterborne polyurethane composites with highly hydrophobic. J. Appl. Polym. Sci. 2015, 132, 8. [CrossRef]

24. Li, Y.; Yang, Z.Z.; Qiu, H.X.; Dai, Y.G.; Zheng, Q.B.; Li, J.; Yang, J.H. Self-aligned graphene as anticorrosive barrier in waterborne polyurethane composite coatings. J. Mater. Chem. A 2014, 2, 14139-14145. [CrossRef] 
25. Lei, L.; Xia, Z.B.; Zhang, L.; Zhang, Y.H.; Zhong, L. Preparation and properties of amino-functional reduced graphene oxide/waterborne polyurethane hybrid emulsions. Prog. Org. Coat. 2016, 97, 19-27. [CrossRef]

26. Wang, X.; Xing, W.Y.; Song, L.; Yang, H.Y.; Hu, Y.; Yeoh, G.H. Fabrication and characterization of graphene-reinforced waterborne polyurethane nanocomposite coatings by the sol-gel method. Surf. Coat. Technol. 2012, 206, 4778-4784. [CrossRef]

27. Pan, H.; Wang, X.D.; Zhang, Y.D.; Yu, L.G.; Zhang, Z.J. Graphene oxides reduced and modified by hydramines-Potentials as electrode materials of supercapacitors and reinforcing agents of waterborne polyurethane. Mater. Res. Bull. 2014, 59, 117-124. [CrossRef]

28. Hsiao, S.T.; Ma, C.C.; Tien, H.W.; Liao, W.H.; Wang, Y.S.; Li, S.M.; Yang, C.Y.; Lin, S.C.; Yang, R.B. Effect of covalent modification of graphene nanosheets on the electrical property and electromagnetic interference shielding performance of a water-borne polyurethane composite. ACS Appl. Mater. Interfaces 2015, 7, 2817-2826. [CrossRef]

29. Hsiao, S.T.; Ma, C.C.M.; Tien, H.W.; Liao, W.H.; Wang, Y.S.; Li, S.M.; Huang, Y.C. Using a non-covalent modification to prepare a high electromagnetic interference shielding performance graphene nanosheet/water-borne polyurethane composite. Carbon 2013, 60, 57-66. [CrossRef]

30. Lin, S.C.; Ma, C.C.M.; Hsiao, S.T.; Wang, Y.S.; Yang, C.Y.; Liao, W.H.; Li, S.M.; Wang, J.A.; Cheng, T.Y.; Lin, C.W.; et al. Electromagnetic interference shielding performance of waterborne polyurethane composites filled with silver nanoparticles deposited on functionalized graphene. Appl. Surf. Sci. 2016, 385, 436-444. [CrossRef]

31. Luo, X.M.; Zhang, P.; Liu, R.; Li, W.H.; Ge, B.H.; Cao, M. Preparation and physical properties of functionalized graphene/waterborne polyurethane uv-curing composites by click chemistry. Polym. Int. 2016, 65, 415-422. [CrossRef]

32. Tian, K.H.; Su, Z.; Wang, H.; Tian, X.Y.; Huang, W.Q.; Xiao, C. N-doped reduced graphene oxide/waterborne polyurethane composites prepared by in situ chemical reduction of graphene oxide. Compos. Part A 2017, 94, 41-49. [CrossRef]

33. Hu, X.L.; Tian, M.W.; Qu, L.J.; Zhu, S.F.; Han, G.T. Multifunctional cotton fabrics with graphene/polyurethane coatings with far-infrared emission, electrical conductivity, and ultraviolet-blocking properties. Carbon 2015, 95, 625-633. [CrossRef]

34. Kim, H.; Lee, S. Evaluation of laundering durability of electro-conductive textile dip-coated on para aramid knit with graphene/waterborne polyurethane composite. Fiber Polym. 2018, 19, 2351-2358. [CrossRef]

35. Cai, K.W.; Zuo, S.X.; Luo, S.P.; Yao, C.; Liu, W.J.; Ma, J.F.; Mao, H.H.; Li, Z.Y. Preparation of polyaniline/graphene composites with excellent anti-corrosion properties and their application in waterborne polyurethane anticorrosive coatings. RSC Adv. 2016, 6, 95965-95972. [CrossRef]

36. Christopher, G.; Kulandainathan, M.A.; Harichandran, G. Comparative study of effect of corrosion on mild steel with waterborne polyurethane dispersion containing graphene oxide versus carbon black nanocomposites. Prog. Org. Coat. 2015, 89, 199-211. [CrossRef]

37. Li, J.; Cui, J.C.; Yang, J.Y.; Li, Y.Y.; Qiu, H.X.; Yang, J.H. Reinforcement of graphene and its derivatives on the anticorrosive properties of waterborne polyurethane coatings. Compos. Sci. Technol. 2016, 129, 30-37. [CrossRef]

38. Luo, J.; Wang, J.H.; Wen, S.G.; Yu, D.Y.; Wu, Y.T.; Sun, K. Improved corrosion resistance based on aptes-grafted reduced sulfonated graphene/waterborne polyurethane coatings. J. Coat. Technol. Res. 2018, 15, 1107-1115. [CrossRef]

39. Hu, J.; Zhang, F. Self-assembled fabrication and flame-retardant properties of reduced graphene oxide/waterborne polyurethane nanocomposites. J. Therm. Anal. Calorim 2014, 118, 1561-1568. [CrossRef]

40. Cunha, E.; Proenca, M.F.; Pereira, M.G.; Fernandes, M.J.; Young, R.J.; Strutynski, K.; Melle-Franco, M.; Gonzalez-Debs, M.; Lopes, P.E.; Paiva, M.D.C. Water dispersible few-layer graphene stabilized by a novel pyrene derivative at micromolar concentration. Nanomaterials 2018, 8, 675.

41. Viinikanoja, A.; Kauppila, J.; Damlin, P.; Makila, E.; Leiro, J.; Aaritalo, T.; Lukkari, J. Interactions between graphene sheets and ionic molecules used for the shear-assisted exfoliation of natural graphite. Carbon 2014, 68, 195-209. [CrossRef]

42. An, X.; Simmons, T.; Shah, R.; Wolfe, C.; Lewis, K.M.; Washington, M.; Nayak, S.K.; Talapatra, S.; Kar, S. Stable aqueous dispersions of noncovalently functionalized graphene from graphite and their multifunctional high-performance applications. Nano Lett. 2010, 10, 4295-4301. [CrossRef] 
43. Li, D.; Muller, M.B.; Gilje, S.; Kaner, R.B.; Wallace, G.G. Processable aqueous dispersions of graphene nanosheets. Nat. Nanotechnol. 2008, 3, 101-105. [CrossRef] [PubMed]

44. Chen, J.; Yao, B.W.; Li, C.; Shi, G.Q. An improved hummers method for eco-friendly synthesis of graphene oxide. Carbon 2013, 64, 225-229. [CrossRef]

45. Zhang, Y.W.; Ma, H.L.; Zhang, Q.L.; Peng, J.; Li, J.Q.; Zhai, M.L.; Yu, Z.Z. Facile synthesis of well-dispersed graphene by gamma-ray induced reduction of graphene oxide. J. Mater. Chem. 2012, 22, 13064-13069. [CrossRef]

46. Ferrari, A.C.; Basko, D.M. Raman spectroscopy as a versatile tool for studying the properties of graphene. Nat. Nanotechnol. 2013, 8, 235-246. [CrossRef]

47. Ferrari, A.C.; Robertson, J. Interpretation of raman spectra of disordered and amorphous carbon. Phys. Rev. B 2000, 61, 14095-14107. [CrossRef]

48. Dong, X.; Shi, Y.; Zhao, Y.; Chen, D.; Ye, J.; Yao, Y.; Gao, F.; Ni, Z.; Yu, T.; Shen, Z.; et al. Symmetry breaking of graphene monolayers by molecular decoration. Phys. Rev. Lett. 2009, 102, 135501. [CrossRef]

49. Papageorgiou, D.G.; Kinloch, I.A.; Young, R.J. Mechanical properties of graphene and graphene-based nanocomposites. Prog. Mater. Sci. 2017, 90, 75-127. [CrossRef]

50. Li, Z.; Young, R.J.; Wang, R.G.; Yang, F.; Hao, L.F.; Jiao, W.C.; Liu, W.B. The role of functional groups on graphene oxide in epoxy nanocomposites. Polymer 2013, 54, 5821-5829. [CrossRef]

51. Damari, S.P.; Cullari, L.; Nadiv, R.; Nir, Y.; Laredo, D.; Grunlan, J.; Regev, O. Graphene-induced enhancement of water vapor barrier in polymer nanocomposites. Compos. Part B-Eng. 2018, 134, 218-224. [CrossRef]

52. Fredrickson, G.H.; Bicerano, J. Barrier properties of oriented disk composites. J. Chem. Phys. 1999, 110, 2181-2188. [CrossRef]

53. Wang, X.; Xing, W.Y.; Feng, X.M.; Yu, B.; Song, L.; Yeoh, G.H.; Hu, Y. Enhanced mechanical and barrier properties of polyurethane nanocomposite films with randomly distributed molybdenum disulfide nanosheets. Compos. Sci. Technol. 2016, 127, 142-148. [CrossRef]

(C) 2019 by the authors. Licensee MDPI, Basel, Switzerland. This article is an open access article distributed under the terms and conditions of the Creative Commons Attribution (CC BY) license (http:/ / creativecommons.org/licenses/by/4.0/). 